\title{
Extraction Current Transients for Selective Charge-Carrier Mobility Determination in Non-Fullerene and Ternary Bulk Heterojunction Organic Solar Cells
}

\author{
Staffan Dahlström, * Xiaoyu Liu, Yajie Yan, Oskar J. Sandberg, Mathias Nyman, Ziqi Liang, \\ and Ronald Österbacka
}

Cite This: ACS Appl. Energy Mater. 2020, 3, 9190-9197

Read Online

ACCESS | Lلll Metrics \& More | 回 Article Recommendations ｜ sl Supporting Information

ABSTRACT: The field of organic solar cells has recently gained broad research interest due to the introduction of non-fullerene small-molecule acceptors. The rapid improvement in solar cell efficiency put increased demand on moving toward scalable device architectures. An essential step toward this is enabling thicker active layers for which the hole and electron mobilities and their ratio become increasingly important. In this work, we demonstrate selective charge-carrier mobility determination using the charge extraction by a linearly increasing voltage (CELIV) method. By tuning the contact properties of the solar cell diodes, the hole and electron mobilities are determined separately using the recently

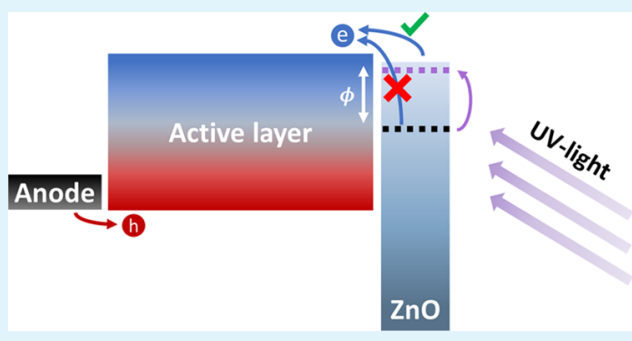
developed metal-intrinsic semiconductor-metal-CELIV (MIM-CELIV) technique. Balanced mobility is measured both in non-fullerene and in ternary blends with the recently published PBBF11 polymer. The mobility results are confirmed using the well-established metal-insulator-semiconductor (MIS) and photo-CELIV techniques.

KEYWORDS: CELIV, organic solar cells, charge transport, charge-carrier mobility, non-fullerene acceptors, ZnO

\section{INTRODUCTION}

Organic solar cells have recently achieved power conversion efficiencies (PCE), reaching $18 \%$ in a lab environment. ${ }^{1}$ An essential factor for the recent advances in PCE for organic solar cells is the development of small-molecule, so-called, nonfullerene acceptors (NFAs). These NFAs are more versatile and tunable by organic chemistry than the previously very commonly used fullerene-based acceptors. Together with the breakthrough of the NFAs, ternary organic solar cells have become more common as an alternative to the traditional binary bulk heterojunction blend. The role of the third component in a ternary blend is not always trivial to clarify, and most likely varies depending on the blend system. ${ }^{2-7} \mathrm{~A}$ noticeable improvement in device performance can be achieved by tuning the band gap of the third component and thereby gaining complementary absorption. In the literature, the third component has also been introduced to improve device stability, optimize morphology, improve charge transport, and reduce recombination, which are all significant challenges for organic solar cells of today. ${ }^{2-7}$ Some of these factors can also be coupled to each other, e.g., optimized morphology can affect both charge transport and recombination.

The charge-carrier mobility is a critical factor for achieving highly efficient organic electronics, and it is, therefore, an important parameter to characterize. Furthermore, due to recent advances in efficiency for organic solar cells, it becomes increasingly important to consider factors important for largescale production and commercialization. For large-scale production, it is vital to move toward thicker active layers suitable for low-cost printing techniques. For thicker layers, the charge transport becomes even more critical, and it is crucial to consider both the hole mobility and the electron mobility separately. ${ }^{8-13}$ A balanced charge-carrier mobility is needed to avoid recombination due to space charge effects in the active layer. ${ }^{14,15}$ The electron mobility in NFAs is typically lower than the electron mobility in conventional fullerene-based acceptors. ${ }^{16-19}$ The introduction of NFAs, which are currently outperforming their fullerene-based counterparts in terms of PCE, means that the electron mobility can be lower than the hole mobility in the resulting bulk heterojunction blends. The NFAs give rise to a possible mobility imbalance and relatively low electron mobility, which can be detrimental for device performance when moving toward thicker layers.

In this work, we demonstrate selective charge-carrier mobility measurements using the charge extraction by a linearly increasing voltage (CELIV) method. The theory was

Received: July 1, 2020

Accepted: August 12, 2020

Published: August 12, 2020 
recently expanded to metal-intrinsic semiconductor-metal (MIM)-type devices, MIM-CELIV, ${ }^{20}$ which together with the established MIS-CELIV and photo-CELIV techniques makes it a versatile method for characterization of charge transport in organic solar cells. ${ }^{21-23}$ Selective mobility determination is performed by tuning the contact properties of the solar cell diodes. By introducing an injection barrier either at the anode or at the cathode in the solar cell device, the MIM-CELIV method can be used for measuring the electron or hole mobility, respectively. Notably, utilizing the UV-soaking effect of the $\mathrm{ZnO}$ interlayer at the cathode, no change in the device structure is needed.

Using these techniques, the charge transport in a recently developed polymer, PBBF11, has been studied in both a ternary blend with a fullerene-based acceptor $\left(\mathrm{PC}_{71} \mathrm{BM}\right)$ and an NFA (ITIC) as well as in a binary blend with only an NFA (ITIC). The same blends as used here have been introduced and optimized for use in organic solar cells in ref 24, where the addition of $\mathrm{PC}_{71} \mathrm{BM}$ is shown to result in an optimized morphology and an improved PCE. Here, we clarify the impact of the addition of $\mathrm{PC}_{71} \mathrm{BM}$ on charge-carrier mobility.

\section{EXPERIMENTAL SECTION}

The following materials: (4,8-bis(5-((2-ethylhexyl)thio)thiophen-2yl)benzo[1,2-b:4,5- $\left.\mathrm{b}^{\prime}\right]$ dithiophene2,6-diyl)bis(trimethylstannane)$\left(\mathrm{Me}_{3} \mathrm{Sn}-\mathrm{BDT}-\mathrm{SnMe}_{3}\right.$ ),1,3-bis(5-bromothiophen-2-yl)-5,7-bis(2-ethylhexyl)-4H,8H-benzo[1,2-c:4,5-c' $]$ dithiophene-4,8-dione $(\mathrm{Br}-$ $\mathrm{BDD}-\mathrm{Br}$ ), and 4,7-bis(5-bromothiophen-2-yl)-5,6-difluoro-2-(2-hexyldecyl)-2H-benzo $[d][1,2,3]$ triazole $(\mathrm{Br}-\mathrm{FTAZ}-\mathrm{Br})$ were purchased from Derthon Optoelectronic Materials Science \& Technology Co., Ltd. $\mathrm{Pd}\left(\mathrm{PPh}_{3}\right)_{4}$ was purchased from J\&K Scientific, Ltd. (China). [6,6]-Phenyl-C71-butyric acid methyl ester $\left(\mathrm{PC}_{71} \mathrm{BM}\right)$ was purchased from Nano-C, Inc. and 3,9-bis(2-methylene-(3-(1,1-dicyanomethylene)-indanone))-5,5,11,11-tetrakis(4-hexylphenyl)-dithieno[2,3-

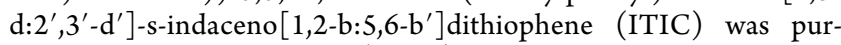
chased from Solarmer, Ltd. (China). Other chemical reagents were purchased from J\&K Scientific, Ltd. (China), Sigma-Aldrich, Ltd. (China) and used as received, except toluene, which was redistilled before utilization. Synthesis for terpolymer PBBF11 was carried out as reported in ref 24.

Device fabrication was performed using the following protocol. Patterned indium tin oxide (ITO) substrates were cleaned successively in an ultrasonic solvent bath of deionized water, acetone, and isopropyl alcohol for $20 \mathrm{~min}$, respectively. Then, the ITO substrates were dried with a heat gun and further treated in an ozone reactor for $20 \mathrm{~min}$. Subsequently, the $\mathrm{ZnO}$ precursor solution was spin-coated onto the precleaned ITO substrates at $5000 \mathrm{rpm}$ for $30 \mathrm{~s}$ and annealed at $200^{\circ} \mathrm{C}$ for $30 \mathrm{~min}$ in air to form a $\mathrm{ZnO}$ layer of $\sim 30$ $\mathrm{nm}$. After cooling to room temperature, the $\mathrm{ZnO}$-coated substrates were transferred to a nitrogen-filled glovebox. Next, PBBF11:ITIC and PBBF11:ITIC:PC ${ }_{71} \mathrm{BM}$ in a chlorobenzene solution (total concentration: $20 \mathrm{mg} / \mathrm{mL}$ ) with weight ratios $1: 1$ and $1: 1: 0.3$, respectively, were spin-coated onto the $\mathrm{ZnO}$-coated substrates at $1800-2200 \mathrm{rpm}$ for $60 \mathrm{~s}$. The thickness of the active layer was $\sim 100$ $\mathrm{nm}$ and the effective area of one cell was $0.04 \mathrm{~cm}^{2}$. Finally, $\mathrm{MoO}_{3}(10$ $\mathrm{nm})$ and $\mathrm{Al}(100 \mathrm{~nm})$ layers were deposited by thermal evaporation under a pressure of $<10^{-4} \mathrm{~Pa}$ at a rate of $\sim 0.2$ and $\sim 1.0 \AA \mathrm{s} / \mathrm{s}$, respectively.

The $J-V$ data were acquired from a Keithley 2400 source-meter unit. The light $J-V$ curves were measured under light illumination with a Newport-Oriel (Sol3A Class AAA Solar Simulator, 94043A) AM $1.5 \mathrm{G}$ light source operating at an intensity of $100 \mathrm{~mW} / \mathrm{cm}^{2}$. The light intensity was calibrated by a certified Oriel reference cell (91150V) and verified with an NREL calibrated, filtered silicon diode (Hamamatsu, S1787-04).

The CELIV measurements were performed using a pulse generator (SRS model DG 535) and a function generator (SRS model DS345) for generating the linearly increasing voltage pulse and an oscilloscope (Tektronix TDS 680B) for recording the current response. All measurements were carried out in a vacuum cryostat to avoid degradation of the devices due to exposure to the ambient atmosphere.

2.1. MIM-CELIV. For the MIM-CELIV measurements, a steadystate offset voltage, $V_{\text {off }}$ smaller than the built-in potential, $V_{\mathrm{bj}}$ is used to vary the number of charge carriers diffusing in from the injecting contacts. The MIM-CELIV measurements differ from the conventional CELIV measurements in the dark, where equilibrium (dopinginduced) carriers uniformly distributed throughout the active layer are assumed. $^{25,26}$ The MIM-CELIV measurement requires at least one injecting contact, in a MIM diode configuration. The mobility is calculated from the time the current transient reaches its maximum value $t_{\max }$ according to

$$
\mu=\frac{k T d^{2}}{\left(V_{\mathrm{bi}}-V_{\mathrm{off}}\right) e A t_{\max }^{2}}
$$

where $d$ is the thickness, $A$ is the voltage rise speed of the linearly increasing voltage, and $k T / e$ is the thermal voltage. ${ }^{20}$

The measured $t_{\max }$ in a CELIV measurement must be much longer than the $R C$-time constant, given by the series resistance $R$ of the external circuit times the capacitance of the device $C=\varepsilon \varepsilon_{0} \times$ area $/ d$, where $\varepsilon$ is the dielectric constant of the active layer and the area refers to the device area. For the MIM-CELIV method, a first approximation for correcting the $R C$ time has been suggested in ref 20 using $\left(t_{\max }-\right.$ $3 R C$ ) instead of $t_{\max }$ for $t_{\max }>5 R C$.

The built-in voltage in eq 1 is, in general, an unknown parameter. However, by varying the offset voltage and plotting the inverse square of $t_{\max }$ as a function of the applied $V_{\text {off }}$ a linear dependence is predicted by eq 1 . The mobility can then be determined from the slope $S$ of the linear fit to the data according to

$$
\mu=\frac{k T d^{2} S}{e A}
$$

and $V_{\mathrm{bi}}$ is determined directly from the intersection of the extrapolated linear fit with the $V_{\text {off }}$ axis. $^{20}$ Note that the theory is valid only for $V_{\text {off }}<V_{\mathrm{bi}}-4 k T / e$.

The more conductive charge-carrier type dominates the MIMCELIV transient. Distinguishing if the electron or hole mobility is measured is often nontrivial since it depends on small differences in injection barriers (determining the carrier density) as well as on the mobility of each carrier type, which are typically unknown parameters. At a similar conductivity and mobilities of the same order of magnitude, the measured mobility using the MIM-CELIV method approaches an arithmetic mean of the mobility of both carrier types instead of the mobility of the faster carrier type. ${ }^{20} \mathrm{UV}$ exposure of the $\mathrm{ZnO}$ layer during the CELIV measurements was done using an Nd:YAG laser (Quantel Ultra) operated at $355 \mathrm{~nm}$.

2.2. MIS-CELIV. MIS-CELIV measurements require a blocking insulating layer in a so-called metal-insulator-semiconductor (MIS) configuration. Charge carriers are injected into the active layer toward the insulator using a steady-state offset voltage, larger than the built-in voltage, to build up a charge-carrier reservoir at the interface between the insulator and the semiconductor layer. A linearly increasing voltage is applied in reverse bias to extract the injected surface charge. The mobility can be determined from the time $t_{1}$ when the total extracted current density $j(t)$ equals twice the magnitude of the displacement current $j_{0}$ given by the geometric capacitance of the device, $j\left(t_{1}\right)=2 j_{0}$. Based on space charge-limited current theory and assuming a drift-dominated current transient, the mobility is then given by

$$
\mu=\frac{\pi^{2} d^{2}}{8 A^{*} t_{1}^{2}}(1+f)
$$

where $A^{*}=A /(1+f)$ and $f=\varepsilon d_{\mathrm{i}} /\left(\varepsilon_{\mathrm{i}} d\right)$ are factors dependent on the geometric capacitance of the insulating layer and the semiconductor layer. $^{23,27}$ The relative dielectric constant of the insulating layer is 
(a)

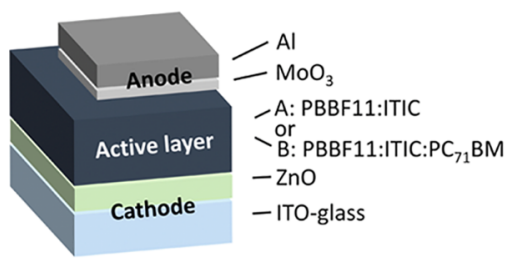

(b)

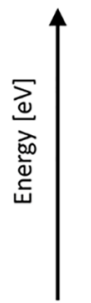

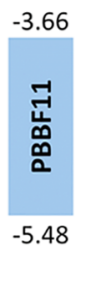

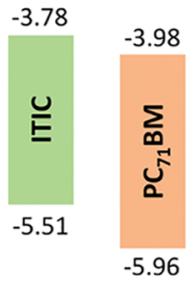

(c)

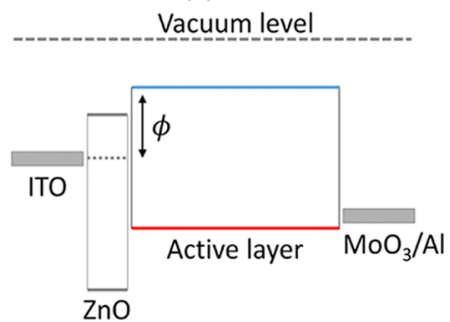

Figure 1. (a) Inverted solar cell device structure used in this study where the active layer is a blend of either A: PBBF11:ITIC or B: PBBF11:ITIC:PC ${ }_{71}$ BM. (b) Energy level diagram of the active layer materials. (c) Schematic sketch of the energy diagram of the solar cell devices is shown. The observed change in $V_{\mathrm{bi}}$ upon $\mathrm{UV}$ irradiation is treated as an effective change in the injection barrier of electrons from the ITO/ZnO contact. The injection barrier is indicated by $\phi$ in the figure.

denoted as $\varepsilon_{\mathrm{i}}$, and the notation $d_{\mathrm{i}}$ stands for the thickness of the insulating layer.

To ensure a drift-dominated space charge-limited extraction current and the validity of the measurement analysis, it is important to apply a high enough $A^{*} t_{1}$. This can be evaluated by plotting the extracted mobility as a function of the applied $A^{*} t_{1}$, as explained by Sandberg et al. ${ }^{21}$ Furthermore, in the case of an ohmic injecting contact, the effect of charges diffusing into the bulk of the active layer from the injecting contact and the injected reservoir affects the current transient. This effect can be corrected in the mobility determination using the following equation

$$
\mu=\frac{\pi^{2} d^{2}}{8 A^{*} t_{1}^{2}}(1+f)\left[1+\frac{\pi^{4} k T}{2 e A^{*} t_{1}}\right]^{-1}
$$

which is valid for an ohmic injecting contact and for $A^{*} t_{1} \gg k T / e^{21}$

2.3. Photo-CELIV. Photo-CELIV measurements were performed using a pulsed Nd:YAG laser (Quantel Ultra) operated at $532 \mathrm{~nm}$. The laser pulse generates charges in the bulk of the $100 \mathrm{~nm}$ thick solar cells through the transparent ITO/ZnO contact, and a linearly increasing voltage pulse is applied after a short delay to extract the photogenerated charge. A small, steady-state offset voltage (similar to $V_{\mathrm{bi}}$ ) is applied in forward bias to prevent the extraction of photogenerated charges during the delay between the laser pulse and the linearly increasing applied voltage pulse. The charge-carrier mobility can be calculated from the time of the extraction current maximum according to the following equation

$$
\mu=K^{2} \frac{2 d^{2}}{3 A t_{\max }^{2}}
$$

where $K$ is a correction factor taking into account the effect of space charge and the charge-carrier distribution in the active layer. Assuming a uniform distribution of the generated charge in the active layer and imbalanced mobility, $K$ is given by

$$
K=\frac{\sqrt{3}}{2}\left[\frac{1}{6.2\left(1+0.002 \frac{\Delta j\left(t_{\max }\right)}{j_{0}}\right)}+\frac{1}{1+0.12 \frac{\Delta j\left(t_{\max }\right)}{j_{0}}}\right]
$$

in the, so-called, moderate conductivity regime, when the timedependent extraction current $\Delta j\left(t_{\max }\right) \approx j_{0}{ }^{28}{ }^{28}$ The correction factor in eq 6 is very commonly used for the analysis of photo-CELIV measurements, however, for balanced mobility, the correction factor becomes $K=1$ in both the moderate and the low conductivity $\left(\Delta j\left(t_{\max }\right) \ll j_{0}\right)$ regimes, as shown in ref 29 .

\section{RESULTS AND DISCUSSION}

The charge-carrier mobility of two different active layer bulk heterojunctions has been studied in detail. A binary nonfullerene system consisting of PBBF11:ITIC at a 1:1 weight ratio was referred to as the active layer $\mathrm{A}$ and a ternary blend

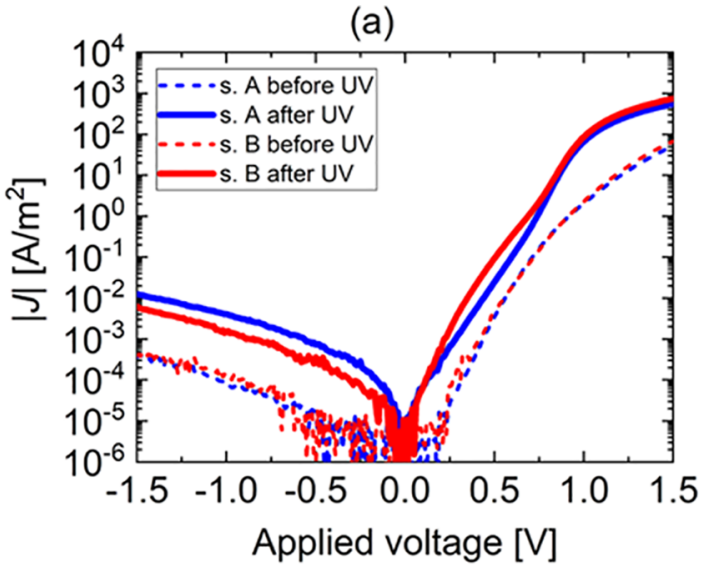

(b)

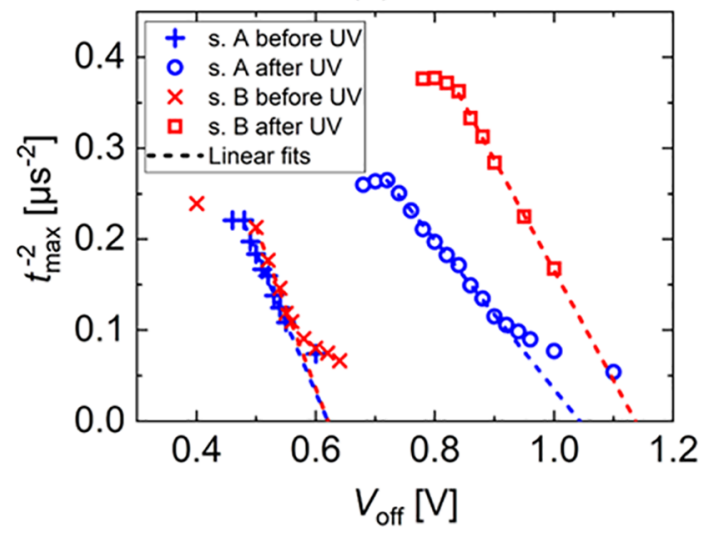

Figure 2. Effect of UV soaking on the device structure A: ITO/ $\mathrm{ZnO} /$ PBBF11:ITIC/ $\mathrm{MoO}_{3} / \mathrm{Al}$ (s. A), and on the device structure B: ITO/ $\mathrm{ZnO} / \mathrm{PBBF} 11: \mathrm{ITIC}: \mathrm{PC}_{71} \mathrm{BM} / \mathrm{MoO}_{3} / \mathrm{Al}$ (s. B). (a) Dark $J-V$ curves before and after UV exposure. (b) Plot of the inverse square of $t_{\max }$ as a function of $V_{\text {off }}$ as measured by the MIM-CELIV method. The builtin potential $V_{\mathrm{bi}}$ is determined by the intersection of the linear fit with the $V_{\text {off }}$ axis, $\mu_{\mathrm{p}}$ is determined from the slope before UV exposure, and the slope after UV exposure determines the ambipolar mobility $\mu_{\mathrm{MIM}}$.

consisting of PBBF11:ITIC:PC ${ }_{71} \mathrm{BM}$ at a 1:1:0.3 weight ratio was referred to as the active layer $B$. These systems have previously been demonstrated to have a high performance around $10 \%$ PCE, with a slightly higher performance of the ternary blend reaching a PCE of $11.4 \%$ without any solvent additives or annealing steps. ${ }^{24}$

In this study, an ITO $/ \mathrm{ZnO}$ cathode was used as the transparent bottom electrode, and $\mathrm{MoO}_{3} / \mathrm{Al}$ was used as the top anode electrode in all devices forming a, so-called, inverted 


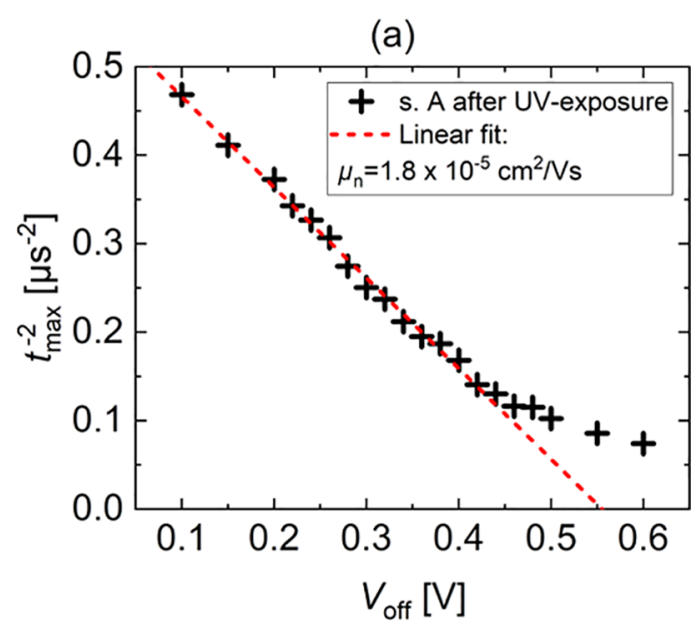

(b)

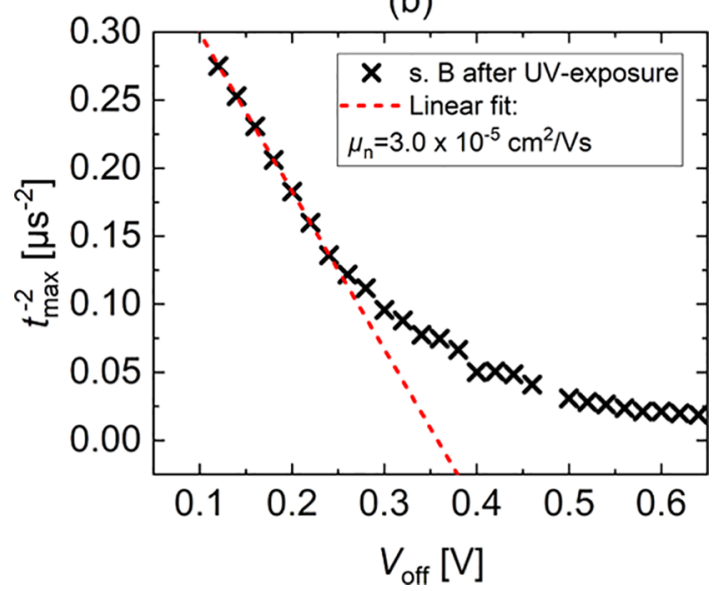

Figure 3. Electron mobility for the active layer A (a) and for the active layer B (b) as measured by MIM-CELIV on electron-only devices. Mobility is determined from the slope of the linear fit to the inverse square of $t_{\max }$ as a function of $V_{\text {off }}$.

device structure. The complete device architecture is illustrated in Figure 1a. The properties of n-type metal oxides, such as $\mathrm{ZnO}$, are known to change when exposed to UV light, and the change is often attributed to chemisorption of oxygen on the $\mathrm{ZnO}$ surface. ${ }^{30-34}$ In other words, oxygen on the $\mathrm{ZnO}$ surface captures electrons and forms a space charge of negative oxygen ions on the $\mathrm{ZnO}$ surface. These adsorbed oxygen ions can be released upon UV irradiation when free charge carriers generated in the $\mathrm{ZnO}$ neutralize the adsorbed oxygen ions.

The UV-soaking effect of $\mathrm{ZnO}$ has been observed in the organic solar cells measured in this work as a change in the measured built-in potential of the solar cell and an increased injected current through the device in the $J-V$ measurements upon UV exposure. In Figure 1c, a schematic of the energy band diagram of the device is shown, where the UV-soaking effect of the ITO/ZnO contact has been illustrated as an effective work function change of the cathode, forming an injection barrier before UV exposure. This feature of the $\mathrm{ZnO}$ layer has been utilized for selective determination of the hole and electron mobilities, as explained in more detail later, without changing the substrate or the bottom contact. Consequently, any change in the morphology and a concomitant change in the charge-carrier mobility of the blend due to film formation on different substrates during device manufacturing is avoided. Figure $1 \mathrm{~b}$ shows the energy level of the highest occupied molecular orbital (HOMO) and the lowest unoccupied molecular orbital (LUMO) of the active layer materials, as reported in ref 24 . The $J-V$ curves in the dark and under one sun illumination of structures A and B are shown in Figure S1 in the Supporting Information.

To measure the charge-carrier mobility selectively using the MIM-CELIV method, the UV-soaking effect of the $\mathrm{ZnO}$ layer was utilized. Figure 2a,b shows the dark $J-V$ and the MIMCELIV measurement data, respectively, before and after UV soaking. The corresponding MIM-CELIV transients are shown in Figure S2. Upon UV treatment, the injected current in the $J-V$ measurement increases by roughly an order of magnitude in forward bias, meaning that the injection of electrons becomes much more efficient after UV exposure. In Figure $2 b$, using the MIM-CELIV method and eqs 1 and 2, it is demonstrated that the built-in potential increases from $V_{\mathrm{bi}}=$ 0.62 to $1.04 \mathrm{~V}$ for sample structure $\mathrm{A}$ and from $V_{\mathrm{bi}}=0.62$ to $1.14 \mathrm{~V}$ for sample structure $\mathrm{B}$. The charge-carrier type with the higher conductivity, $\sigma=e \mu n$ where $n$ is the charge-carrier density, dominates the extraction current transients and the mobility of the more conductive charge is thereby measured. Before UV exposure, a significant injection barrier at the cathode reduces the number of electrons diffusing into the active layer, and the device in the dark can be considered as hole-only. After UV treatment, both the cathode and anode should form an ohmic contact for the injection of electrons and holes, respectively. The measured $V_{\mathrm{bi}}$ can be interpreted as a transition from a hole-dominated device to an ambipolar device, supported by the dark $J-V$ data. Note that the absolute value of $V_{\mathrm{bi}}$ after exposure to a laser light at $355 \mathrm{~nm}$ does not necessarily correspond to $V_{\mathrm{bi}}$ during operation under one sun. However, the rather high built-in potential above $1 \mathrm{~V}$ is in good agreement with the high $V_{\mathrm{OC}}=0.92 \mathrm{~V}$ and the large effective band gap due to the deep-lying HOMO level of PBBF11, see Figure 1b. Note that the UV exposure was kept as short as possible to avoid degradation of the solar cell stack. A dose of less than $1500 \mathrm{~mJ} / \mathrm{cm}^{2}$ was enough for saturation of the UV-soaking effect of the $\mathrm{ZnO}$.

For sample structure A, it is seen that the mobility slightly decreases upon UV soaking from $\mu_{\mathrm{p}, \mathrm{MIM}}=2.6 \times 10^{-5} \mathrm{~cm}^{2} / \mathrm{Vs}$ to $\mu_{\mathrm{MIM}}=1.4 \times 10^{-5} \mathrm{~cm}^{2} /$ Vs. For sample structure $\mathrm{B}$, the change in mobility is even smaller, from $\mu_{\mathrm{p}, \mathrm{MIM}}=3.0 \times 10^{-5}$ $\mathrm{cm}^{2} /$ Vs to $\mu_{\mathrm{MIM}}=2.1 \times 10^{-5} \mathrm{~cm}^{2} /$ Vs. The small change indicates that either holes still dominate the current transient after UV exposure or the electron and hole mobilities are very similar. For similar electron and hole mobilities and conductivities, the measured ambipolar mobility is expected to approach the arithmetic mean of the actual electron and hole mobilities. The results indicate that the electron mobility could be slightly higher in sample B than in sample A. The differences are, however, minimal, and the mobility has been further characterized in the following sections to clarify any difference between active layers $\mathrm{A}$ and $\mathrm{B}$.

To directly measure the electron mobility, electrondominated devices with an injection barrier for holes at the anode are required. One batch of devices with a degraded and thereby noninjecting $\mathrm{MoO}_{3} / \mathrm{Al}$ top contact was characterized for this purpose. The likely reason for the poor injection from the $\mathrm{MoO}_{3} / \mathrm{Al}$ contact is the oxidation of the $\mathrm{Al}$ top contact during shipment. For these devices, both contacts are noninjecting before UV exposure, and after UV exposure, the ITO/ZnO contact becomes electron-injecting, i.e., an electrononly device is formed. The $t_{\max }^{-2}\left(V_{\text {off }}\right)$-plot from the MIM- 
(a)

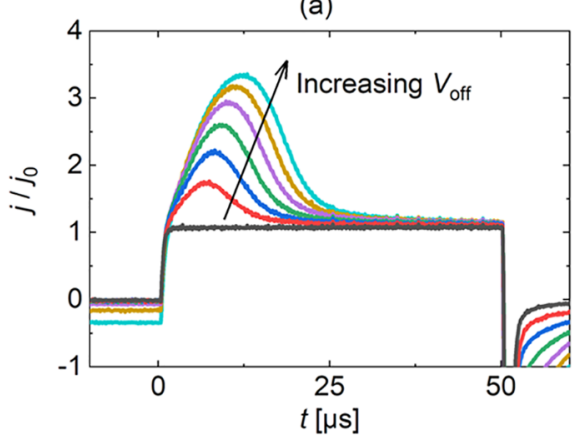

(c)

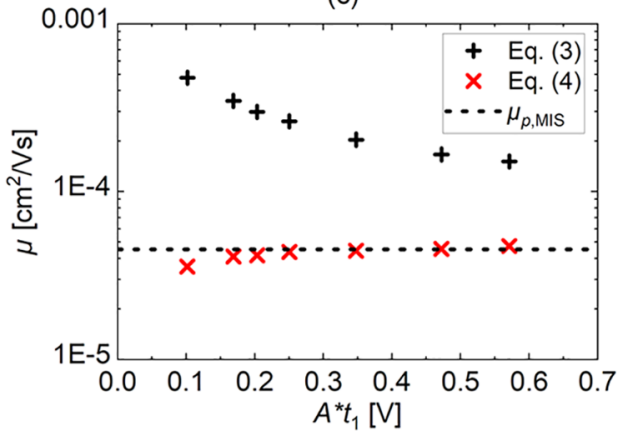

(b)

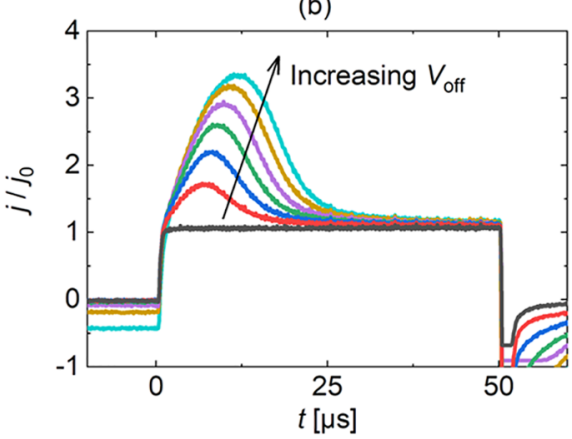

(d)

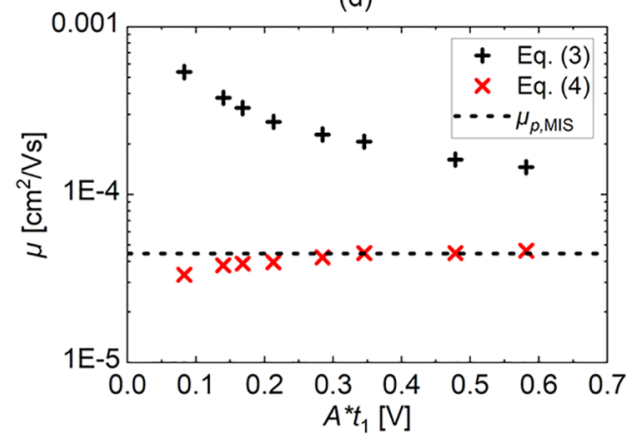

Figure 4. CELIV transients for sample A (a) and for sample B (b) showing the build-up of a hole reservoir at the $\mathrm{ZnO}$ cathode with increasing $V_{\text {off }}$ starting at $0 \mathrm{~V}$ (black) and going from 0.7 to $1.2 \mathrm{~V}$ in steps of $0.1 \mathrm{~V}$. The voltage rise speed is $A=4 \mathrm{~V} / 50 \mu \mathrm{s}$ for the transients (a) and (b). The extracted MIS-CELIV mobility as a function of $A^{*} t_{1}$ is plotted in (c) for sample A, and in (d) for sample B. The black symbols show the mobilities, as calculated using eq 3 , and the red symbols show the mobility determined using the correction in eq 4 . The dotted lines in (c) and (d) show the average mobility, given by eq 4 , in the valid measurement regime, where $A^{*} t_{1}>0.25 \gg k T / e$.

CELIV measurements of UV-treated electron-only devices are shown for sample A in Figure $3 \mathrm{a}$ and for sample B in Figure $3 \mathrm{~b}$. Examples of the measured MIM-CELIV transients are shown in Figure S3. A large injection barrier for holes in these devices is confirmed by the MIM-CELIV measurements in Figure 3, where $V_{\mathrm{bi}}$ after UV exposure is much smaller than in the ambipolar devices, as shown in Figure 2. The exact absolute value for $V_{\mathrm{bi}}$ is of less importance since it is dependent on the unknown energy level for the degraded $\mathrm{MoO}_{3} / \mathrm{Al}$ top contact somewhere in the middle of the effective band gap of the device. The $J-V$ curves in the dark before and after UV treatment, as shown in Figure S3, validates the noninjecting behavior of the contacts before UV exposure. The mobility results confirm the slight increase in $\mu_{\mathrm{n}}$, from $\mu_{\mathrm{n}, \mathrm{MIM}}=1.8 \times$ $10^{-5}$ to $3.0 \times 10^{-5} \mathrm{~cm}^{2} / \mathrm{Vs}$, upon the addition of PCBM in sample structure B, as anticipated from the results in Figure 2.

To further confirm the validity of the determined mobility values, the well-established MIS-CELIV and photo-CELIV techniques were used. The hole mobility of both sample structures A and B was measured by MIS-CELIV, $\mu_{p \text {,MIS. The }}$ electron-selective $\mathrm{ZnO}$ layer was used as the hole-blocking layer before UV exposure, where no injection of electrons takes place. Current transients at different offset voltages are shown in Figure $4 \mathrm{a}, \mathrm{b}$, demonstrating the hole-blocking properties of the $\mathrm{ZnO}$ layer. The surface recombination, $S_{\mathrm{R}}$, of holes at the $\mathrm{ZnO} /$ active layer interface has been extracted from the MISCELIV transients to quantify the hole-blocking properties of the $\mathrm{ZnO}$ layer. For sample structure A, $S_{\mathrm{R}}=1.8 \times 10^{-3} \mathrm{~cm} / \mathrm{s}$, and for the structure $\mathrm{B}, S_{\mathrm{R}}=3.0 \times 10^{-3} \mathrm{~cm} / \mathrm{s}$, which is low enough for enabling the build-up of a hole reservoir at the interface. The details about the $S_{\mathrm{R}}$-measurement are given in the Supporting Information in Figure S4. ${ }^{35}$
The extracted MIS-CELIV mobilities using eqs 3 and 4 are plotted as a function of the applied $A^{*} t_{1}$. We assume that the top $\mathrm{MoO}_{3} / \mathrm{Al}$ contact acts as an ohmic hole-injecting contact. For low $A^{*} t_{1}$, the mobility is then overestimated due to the diffused charge from the ohmic contact, but at higher $A^{*} t_{1}$, the extracted mobility approaches the actual mobility, as described in ref 21 . For these devices, a high enough $A^{*} t_{1}$ for the extracted $\mu_{\mathrm{p}, \mathrm{MIS}}$ to saturate close to the actual mobility, showing a constant value as a function of $A^{*} t_{1}$, cannot be applied due to $R C$-time limitations and the risk of dielectric breakdown. The $R C$ time in these devices is slightly less than $0.1 \mu \mathrm{s}$ at $50 \mathrm{ohm}$. The mobility extracted using eq 4 takes into account the diffusion of charge carriers from the ohmic top contact and outputs constant mobility in the valid regime at $A^{*} t_{1} \gg k T / e$, as seen in Figure $4 c$ for sample structure A and in Figure $4 \mathrm{~d}$ for sample structure B. This analysis confirms that the assumption of ohmic injection from the $\mathrm{MoO}_{3} / \mathrm{Al}$ contact is correct for these samples. Both sample structures give the same hole mobility of $4.5 \times 10^{-5} \mathrm{~cm}^{2} / \mathrm{Vs}$.

The temperature dependence of the ambipolar mobility for both device structures A and B was measured using photoCELIV for temperatures ranging from 295 to $170 \mathrm{~K}$. Equation 5 and $K=1$ were used for mobility determination due to the previously measured balanced mobility. The Gaussian disorder model $^{36}$ was used to fit the data and determine the width of the Gaussian density of states (DOS), $\sigma_{\mathrm{DOS}}$

$$
\mu_{\mathrm{GDM}}(T, E=0)=\mu_{\infty} \exp \left[-\left(\frac{2 \sigma_{\mathrm{DOS}}}{3 k T}\right)^{2}\right]
$$

where $\mu_{\infty}$ is the zero-field mobility when $T \rightarrow \infty$. An example of a photo-CELIV transient for both device structures $A$ and $B$ at 
(a)

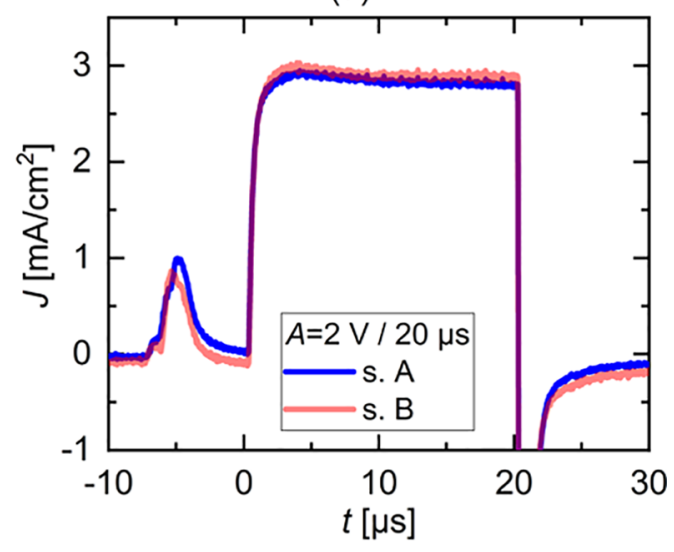

(b)

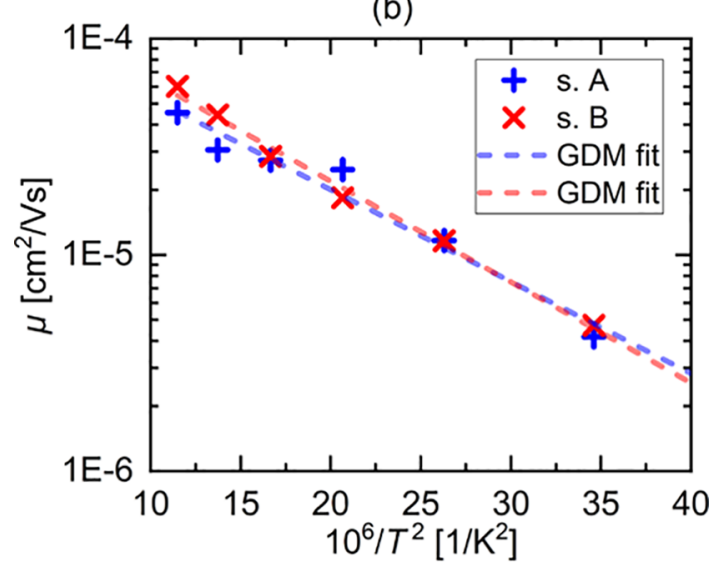

Figure 5. Photo-CELIV transients at room temperature for device structures A and B (a). Temperature dependence of the ambipolar mobility $\mu$, as measured by the photo-CELIV method (b), where $\mu$ is plotted versus $10^{6} / T^{2}$. The width of the Gaussian DOS, $\sigma_{\mathrm{DOS}}$, is determined from the linear fit as depicted by the Gaussian disorder model $(\mathrm{GDM}) ; \sigma_{\mathrm{DOS}}=40 \pm 12 \mathrm{meV}$ for sample A and $\sigma_{\mathrm{DOS}}=42 \pm 9$ $\mathrm{meV}$ for sample $\mathrm{B}$.

room temperature is plotted in Figure 5a and the extracted mobilities are plotted in Figure 5b with the mobility on a log scale as a function of the inverse square of the temperature, $T$. A reasonable linear dependence is seen for both sample structures $A$ and $B$, as predicted by eq 7 . By making a linear fit to the plot in Figure $5 \mathrm{~b}$, the width of the DOS, $\sigma_{\mathrm{DOS}}$, can be determined. The temperature dependence is very similar for both active layers, and from the fits we also acquire very similar energetic disorder for both device structures; $\sigma_{\mathrm{DOS}}=40 \pm 12$ meV for sample A and $\sigma_{\mathrm{DOs}}=42 \pm 9 \mathrm{meV}$ for sample $\mathrm{B}$. Despite the rather low mobility in these blends, these results suggest a relatively narrow energetic disorder compared to values reported in the literature for some of the most wellstudied benchmark materials for organic solar cells, such as P3HT:PCBM, PTB7:PC ${ }_{71}$ BM, PTB7-Th:ITIC, and PM6:Y6, ranging from $\sigma_{\mathrm{DOS}}=48$ to $86 \mathrm{meV} .{ }^{17,37-39}$ However, the width of the DOS is not solely responsible for the charge-carrier mobility; parameters such as the intermolecular distance and the delocalization length also have an impact. The Gaussian disorder model assumes an empty DOS, which is often not the case in thin devices with ohmic contacts. This might give rise to errors in the analysis, and we have therefore also considered an Arrhenius plot, as shown in Figure S5, assuming a thermally activated mobility following a $1 / T$ dependence. ${ }^{40}$ Since the temperature dependence is very similar for both structures, this analysis gives similar results for both structures as well; the fitted activation energy is $77 \mathrm{meV}$ for sample structure A and $86 \mathrm{meV}$ for sample structure B.

The mobility as determined by each method is summarized in Table 1 ; note that $\mu_{\mathrm{MIM}}$ and $\mu_{\text {photo }}$ give the ambipolar mobility or the mobility of the more conductive carrier type in the device. From the summary, it is straightforward to conclude that mobility is very similar for both blends. The MIM-CELIV method is expected to give slightly lower mobility since it is an equilibrium method, as has been demonstrated earlier. ${ }^{41}$ The MIM-CELIV data on hole-only and electron-only devices suggest that the hole mobility is slightly higher than the electron mobility for the binary blend (active layer A), whereas the ternary blend (active layer B) would have more balanced mobility. However, the differences are minimal (less than a factor of two), which means that the mobilities are essentially balanced in both systems considering the accuracy of charge-carrier mobility measurements in disordered systems. ${ }^{41,42}$ In other words, there is no, or a minimal, effect on the mobility upon adding $\mathrm{PC}_{71} \mathrm{BM}$ to the blend. The rather balanced mobility in both systems are encouraging regarding thicker devices, however, the low absolute mobility values are a limitation. We note that the measured ambipolar mobility using MIM-CELIV turns out slightly lower than both the measured electron and hole mobility. However, this difference is also smaller than the accuracy of mobility measurements. For almost balanced mobility (difference less than a factor of two), as reported here, and equal injection barriers at the contacts, the measured ambipolar mobility by MIM-CELIV is given by the arithmetic mean of $\mu_{\mathrm{n}}$ and $\mu_{\mathrm{p}}$, as suggested by drift-diffusion simulations in ref 20 and not by the carrier with higher mobility.

\section{CONCLUSIONS}

Selective determination of the charge-carrier mobility in organic solar cells using the MIM-CELIV method has been demonstrated. The selective mobility measurements require good control of the contact properties of the solar cell diodes. The UV-soaking effect of the $\mathrm{ZnO}$ interlayer on the built-in potential has been measured directly in the solar cell devices, and the effect is utilized for the selective mobility measurements. In addition, the electron-selective properties of the $\mathrm{ZnO}$ layer are used for MIS-CELIV measurements, also directly using the same solar cell structure. Apart from the

Table 1. Summary of the Mobilities as Determined by MIM-CELIV ( $\mu_{\mathrm{p}, \mathrm{MIM}}, \boldsymbol{\mu}_{\mathrm{n}, \mathrm{MIM}}$, and $\left.\boldsymbol{\mu}_{\mathrm{MIM}}\right)$, Photo-CELIV ( $\left.\boldsymbol{\mu}_{\mathrm{photo}}\right)$, and MIS-CELIV ( $\left.\boldsymbol{\mu}_{p, \mathrm{MIS}}\right)$ at Room Temperature

$\begin{array}{ccccc}\text { sample } & \mu_{\mathrm{p}, \mathrm{MIM}}\left[\frac{\mathrm{cm}^{2}}{\mathrm{Vs}}\right] & \mu_{\mathrm{n}, \mathrm{MIM}\left[\frac{\mathrm{cm}^{2}}{\mathrm{Vs}}\right]} & \mu_{\mathrm{MIM}}\left[\frac{\mathrm{cm}^{2}}{\mathrm{Vs}}\right] & \mu_{\mathrm{p}, \mathrm{MIS}\left[\frac{\mathrm{cm}^{2}}{\mathrm{Vs}}\right]} \\ \text { A } & 2.6 \times 10^{-5} & 1.8 \times 10^{-5} & 1.4 \times 10^{-5} & 4.5 \times 10^{-5} \\ \text { B } & 3.0 \times 10^{-5} & 3.0 \times 10^{-5} & 2.1 \times 10^{-5} & 6.0 \times 10^{-5}\end{array}$


demonstration of selective charge-carrier mobility measurements using the CELIV method, these results demonstrate the versatility of the CELIV technique as a tool for gaining information about the contact properties of organic solar cells as well, such as built-in potential and surface recombination at the contacts. The method can, therefore, be useful in conjunction with other characterization techniques for a more complete picture of the contact properties. ${ }^{43}$

The use of a ternary blend in the bulk of organic solar cells can have several advantages and has previously been shown to optimize the morphology and suppress charge recombination in the ternary blend systems studied here. ${ }^{24}$ However, this research work shows that the ternary component only has a minor effect on the charge-carrier mobility in these particular systems. The temperature-dependent mobility data also suggest that there is no significant effect on the transport properties upon the addition of $\mathrm{PC}_{71} \mathrm{BM}$ to the blend.

Balanced electron and hole mobilities of PBBF11 blended with the benchmark non-fullerene acceptor ITIC for a binary system or ITIC and the fullerene derivative $\mathrm{PC}_{71} \mathrm{BM}$ for a ternary system have been measured. The selective and ambipolar mobility measurements result in absolute mobility values in the range between $1 \times 10^{-5}$ and $6 \times 10^{-5} \mathrm{~cm}^{2} / \mathrm{Vs}$, depending on the technique used for the measurements. In agreement with previous measurements, the recently developed MIM-CELIV method gives slightly lower values than the well-established photo-CELIV technique, which measures photogenerated charge, and the MIS-CELIV technique, which measures extraction currents based on space chargelimited currents. ${ }^{41}$ Balanced mobility, as measured here, is an especially important criterion for solar cells with thicker active layers suitable for large-scale production, although the reported relatively low absolute mobility values are not very promising in this regard.

\section{ASSOCIATED CONTENT}

\section{S1 Supporting Information}

The Supporting Information is available free of charge at https://pubs.acs.org/doi/10.1021/acsaem.0c01539.

$J-V$ curves of the solar cells, and MIM-CELIV transients and details about determining the surface recombination velocity based on the MIS-CELIV measurements (PDF)

\section{AUTHOR INFORMATION}

\section{Corresponding Author}

Staffan Dahlström - Physics, Faculty of Science and Engineering, Åbo Akademi University, 20500 Turku, Finland; ○ orcid.org/0000-0002-9328-9637; Email: stdahlst@abo.fi

\section{Authors}

Xiaoyu Liu - Department of Materials Science, Fudan University, Shanghai 200433, China

Yajie Yan - Department of Materials Science, Fudan University, Shanghai 200433, China

Oskar J. Sandberg - Department of Physics, Swansea University, Swansea SA2 8PP, Wales, United Kingdom

Mathias Nyman - Physics, Faculty of Science and Engineering, Åbo Akademi University, 20500 Turku, Finland; (이이.org/ 0000-0002-1250-7111

Ziqi Liang - Department of Materials Science, Fudan University, Shanghai 200433, China; 10 orcid.org/0000-0003-45816487
Ronald Österbacka - Physics, Faculty of Science and Engineering, Åbo Akademi University, 20500 Turku, Finland; (1) orcid.org/0000-0003-0656-2592

Complete contact information is available at:

https://pubs.acs.org/10.1021/acsaem.0c01539

\section{Author Contributions}

The paper was written through contribution of all authors. All authors have approved the final version of the paper.

\section{Funding}

Financial support from Jane \& Aatos Erkko Foundation (project ASPIRE) is acknowledged. SD acknowledges funding from the Vilho, Yrjö and Kalle Väisälä Foundation and the Society of Swedish Literature in Finland. MN acknowledges partial funding from the Academy of Finland through project \#326000. ZL acknowledges the support by Inter-Governmental International Cooperation Projects of Science and Technology Commission of Shanghai Municipality (STCSM) under grant no. 17520710100.

\section{Notes}

The authors declare no competing financial interest.

\section{ACKNOWLEDGMENTS}

The authors thank Christian Ahläng, Sebastian Wilken, and Nora Wilson for valuable discussions and constructive feedback during the finalization of the paper.

\section{REFERENCES}

(1) Liu, Q.; Jiang, Y.; Jin, K.; Qin, J.; Xu, J.; Li, W.; Xiong, J.; Liu, J.; Xiao, Z.; Sun, K.; Yang, S.; Zhang, X.; Ding, L. 18\% Efficiency Organic Solar Cells. Sci. Bull. 2020, 65, 272-275.

(2) Fu, H.; Wang, Z.; Sun, Y. Advances in Non-Fullerene Acceptor Based Ternary Organic Solar Cells. Sol. RRL 2018, 2, No. 1700158.

(3) Xie, Y.; Yang, F.; Li, Y.; Uddin, M. A.; Bi, P.; Fan, B.; Cai, Y.; Hao, X.; Woo, H. Y.; Li, W.; Liu, F.; Sun, Y. Morphology Control Enables Efficient Ternary Organic Solar Cells. Adv. Mater. 2018, 30, $1-8$

(4) Doumon, N. Y.; Houard, F. V.; Dong, J.; Christodoulis, P.; Dryzhov, M. V.; Portale, G.; Koster, L. J. A. Improved Photostability in Ternary Blend Organic Solar Cells: The Role of [70]PCBM. J. Mater. Chem. C 2019, 7, 5104-5111.

(5) Gasparini, N.; Salleo, A.; McCulloch, I.; Baran, D. The Role of the Third Component in Ternary Organic Solar Cells. Nat. Rev. Mater. 2019, 4, 229-242.

(6) Zhu, T.; Zheng, L.; Xiao, Z.; Meng, X.; Liu, L.; Ding, L.; Gong, $\mathrm{X}$. Functionality of Non-Fullerene Electron Acceptors in Ternary Organic Solar Cells. Sol. RRL 2019, 3, No. 1900322.

(7) Gasparini, N.; Paleti, S. H. K.; Bertrandie, J.; Cai, G.; Zhang, G.; Wadsworth, A.; Lu, X.; Yip, H.-L.; McCulloch, I.; Baran, D. Exploiting Ternary Blends for Improved Photostability in High-Efficiency Organic Solar Cells. ACS Energy Lett. 2020, 5, 1371-1379.

(8) Street, R. A. Carrier Mobility, Structural Order, and Solar Cell Efficiency of Organic Heterojunction Devices. Appl. Phys. Lett. 2008, 93, 2012-2015.

(9) Inche Ibrahim, M. L.; Ahmad, Z.; Sulaiman, K.; Muniandy, S. V. Combined Influence of Carrier Mobility and Dielectric Constant on the Performance of Organic Bulk Heterojunction Solar Cells. AIP Adv. 2014, 4, No. 057133.

(10) Bartesaghi, D.; Pérez, I. D. C.; Kniepert, J.; Roland, S.; Turbiez, M.; Neher, D.; Koster, L. J. A. Competition between Recombination and Extraction of Free Charges Determines the Fill Factor of Organic Solar Cells. Nat. Commun. 2015, 6, No. 7083.

(11) Shoaee, S.; Stolterfoht, M.; Neher, D. The Role of Mobility on Charge Generation, Recombination, and Extraction in Polymer-Based Solar Cells. Adv. Energy Mater. 2018, 8, 1-20. 
(12) Meredith, P.; Armin, A. Scaling of next Generation Solution Processed Organic and Perovskite Solar Cells. Nat. Commun. 2018, 9, No. 5261.

(13) Bartelt, J. A.; Lam, D.; Burke, T. M.; Sweetnam, S. M.; McGehee, M. D. Charge-Carrier Mobility Requirements for Bulk Heterojunction Solar Cells with High Fill Factor and External Quantum Efficiency $>90 \%$. Adv. Energy Mater. 2015, 5, 1-10.

(14) Firdaus, Y.; Le Corre, V. M.; Khan, J. I.; Kan, Z.; Laquai, F.; Beaujuge, P. M.; Anthopoulos, T. D. Key Parameters Requirements for Non-Fullerene-Based Organic Solar Cells with Power Conversion Efficiency $>20 \%$. Adv. Sci. 2019, 6, No. 1802028.

(15) Wilken, S.; Sandberg, O. J.; Scheunemann, D.; Österbacka, R. Watching Space Charge Build Up in an Organic Solar Cell. Sol. RRL 2020, 4, No. 1900505

(16) Zhang, X.; Zuo, X.; Xie, S.; Yuan, J.; Zhou, H.; Zhang, Y. Understanding Charge Transport and Recombination Losses in High Performance Polymer Solar Cells with Non-Fullerene Acceptors. J. Mater. Chem. A 2017, 5, 17230-17239.

(17) Yi, X.; Gautam, B.; Constantinou, I.; Cheng, Y.; Peng, Z.; Klump, E.; Ba, X.; Ho, C. H. Y.; Dong, C.; Marder, S. R.; Reynolds, J. R.; Tsang, S. W.; Ade, H.; So, F. Impact of Nonfullerene Molecular Architecture on Charge Generation, Transport, and Morphology in PTB7-Th-Based Organic Solar Cells. Adv. Funct. Mater. 2018, 28, 19.

(18) Xiao, B.; Song, J.; Guo, B.; Zhang, M.; Li, W.; Zhou, R.; Liu, J.; Wang, H. B.; Zhang, M.; Luo, G.; Liu, F.; Russell, T. P. Improved Photocurrent and Efficiency of Non-Fullerene Organic Solar Cells despite Higher Charge Recombination. J. Mater. Chem. A 2018, 6, 957-962.

(19) Bauer, N.; Zhang, Q.; Zhao, J.; Ye, L.; Kim, J. H.; Constantinou, I.; Yan, L.; So, F.; Ade, H.; Yan, H.; You, W. Comparing Non-Fullerene Acceptors with Fullerene in Polymer Solar Cells: A Case Study with FTAZ and PyCNTAZ. J. Mater. Chem. A 2017, 5, 4886-4893.

(20) Dahlström, S.; Sandberg, O. J.; Nyman, M.; Österbacka, R. Determination of Charge-Carrier Mobility and Built-In Potential in Thin-Film Organic M-I-M Diodes from Extraction-Current Transients. Phys. Rev. Appl. 2018, 10, No. 054019.

(21) Sandberg, O. J.; Nyman, M.; Dahlström, S.; Sandén, S.; Törngren, B.; Smått, J.-H.; Österbacka, R. On the Validity of MISCELIV for Mobility Determination in Organic Thin-Film Devices. Appl. Phys. Lett. 2017, 110, No. 153504.

(22) Juška, G.; Nekrašas, N.; Genevičius, K.; Stuchlik, J.; Kočka, J. Relaxation of Photoexited Charge Carrier Concentration and Mobility in Mc-Si:H. Thin Solid Films 2004, 451-452, 290-293.

(23) Juška, G.; Nekrašas, N.; Genevičius, K. Investigation of Charge Carriers Transport from Extraction Current Transients of Injected Charge Carriers. J. Non-Cryst. Solids 2012, 358, 748-750.

(24) Liu, X.; Yan, Y.; Honarfar, A.; Yao, Y.; Zheng, K.; Liang, Z. Unveiling Excitonic Dynamics in High-Efficiency Nonfullerene Organic Solar Cells to Direct Morphological Optimization for Suppressing Charge Recombination. Adv. Sci. 2019, 6, No. 1802103.

(25) Juška, G.; Arlauskas, K.; Viliūnas, M.; Kocka, J. Extraction Current Transients: New Method of Study of Charge Transport in Microcrystalline Silicon. Phys. Rev. Lett. 2000, 84, 4946.

(26) Sandberg, O. J.; Nyman, M.; Österbacka, R. Direct Determination of Doping Concentration and Built-in Voltage from Extraction Current Transients. Org. Electron. 2014, 15, 3413-3420.

(27) Armin, A.; Juska, G.; Ullah, M.; Velusamy, M.; Burn, P. L.; Meredith, P.; Pivrikas, A. Balanced Carrier Mobilities: Not a Necessary Condition for High-Efficiency Thin Organic Solar Cells as Determined by MIS-CELIV. Adv. Energy Mater. 2014, 4, No. 1300954.

(28) Lorrmann, J.; Badada, B. H.; Inganäs, O.; Dyakonov, V.; Deibel, C. Charge Carrier Extraction by Linearly Increasing Voltage: Analytic Framework and Ambipolar Transients. J. Appl. Phys. 2010, 108, No. 113705.

(29) Sandberg, O. J.; Nyman, M. Charge Extraction by a Linearly Increasing Voltage of Photo-Generated Carriers: The Influence of
Two Mobile Carrier Types, Bimolecular Recombination, and Series Resistance. Org. Electron. 2019, 64, 97-103.

(30) Wilken, S.; Parisi, J.; Borchert, H. Role of Oxygen Adsorption in Nanocrystalline $\mathrm{ZnO}$ Interfacial Layers for Polymer-Fullerene Bulk Heterojunction Solar Cells. J. Phys. Chem. C 2014, 118, 1967219682.

(31) Madel, M.; Huber, F.; Mueller, R.; Amann, B.; Dickel, M.; Xie, Y.; Thonke, K. Persistent Photoconductivity in $\mathrm{ZnO}$ Nanowires: Influence of Oxygen and Argon Ambient. J. Appl. Phys. 2017, 121, No. 124301.

(32) Jacobs, C. B.; Maksov, A. B.; Muckley, E. S.; Collins, L.; Mahjouri-Samani, M.; Ievlev, A.; Rouleau, C. M.; Moon, J. W.; Graham, D. E.; Sumpter, B. G.; Ivanov, I. N. UV-Activated ZnO Films on a Flexible Substrate for Room Temperature $\mathrm{O} 2$ and $\mathrm{H} 2 \mathrm{O}$ Sensing. Sci. Rep. 2017, 7, No. 6053.

(33) Li, Q. H.; Gao, T.; Wang, Y. G.; Wang, T. H. Adsorption and Desorption of Oxygen Probed from $\mathrm{ZnO}$ Nanowire Films by Photocurrent Measurements. Appl. Phys. Lett. 2005, 86, No. 123117.

(34) Sundqvist, A.; Sandberg, O. J.; Nyman, M.; Smått, J. H.; Österbacka, R. Origin of the S-Shaped JV Curve and the LightSoaking Issue in Inverted Organic Solar Cells. Adv. Energy Mater. 2016, 6, No. 1502265.

(35) Sandberg, O. J.; Sandén, S.; Sundqvist, A.; Smått, J. H.; Österbacka, R. Determination of Surface Recombination Velocities at Contacts in Organic Semiconductor Devices Using Injected Carrier Reservoirs. Phys. Rev. Lett. 2017, 118, No. 076601.

(36) Bässler, H. Charge Transport in Disordered Organic Photoconductors a Monte Carlo Simulation Study. Phys. Status Solidi 1993, $175,15-56$.

(37) Nyman, M.; Sandberg, O. J.; Österbacka, R. Charge Transport in Intercalated and Non-Intercalated Polymer:Fullerene Blends. Synth. Met. 2015, 201, 6-10.

(38) Ebenhoch, B.; Thomson, S. A. J.; Genevičius, K.; Juška, G.; Samuel, I. D. W. Charge Carrier Mobility of the Organic Photovoltaic Materials PTB7 and PC71BM and Its Influence on Device Performance. Org. Electron. 2015, 22, 62-68.

(39) Upreti, T.; Wang, Y.; Zhang, H.; Scheunemann, D.; Gao, F.; Kemerink, M. Experimentally Validated Hopping-Transport Model for Energetically Disordered Organic Semiconductors. Phys. Rev. Appl. 2019, 12, 1 .

(40) Züfle, S.; Altazin, S.; Hofmann, A.; Jäger, L.; Neukom, M. T.; Brütting, W.; Ruhstaller, B. Determination of Charge Transport Activation Energy and Injection Barrier in Organic Semiconductor Devices. J. Appl. Phys. 2017, 122, No. 115502.

(41) Dahlström, S.; Ahläng, C.; Björkström, K.; Forsblom, S.; Granroth, B.; Jansson, K.; Luukkonen, A.; Masood, M. T.; Poulizac, J.; Qudsia, S.; Nyman, M. Extraction Current Transients for Mobility Determination-A Comparative Study. AIP Adv. 2020, 10, No. 065203.

(42) Blakesley, J. C.; Castro, F. A.; Kylberg, W.; Dibb, G. F. A.; Arantes, C.; Valaski, R.; Cremona, M.; Kim, J. S.; Kim, J. S. Towards Reliable Charge-Mobility Benchmark Measurements for Organic Semiconductors. Org. Electron. 2014, 15, 1263-1272.

(43) Neukom, M.; Züfle, S.; Jenatsch, S.; Ruhstaller, B. OptoElectronic Characterization of Third-Generation Solar Cells. Sci. Technol. Adv. Mater. 2018, 19, 291-316. 